\title{
Hydrological long-term dry and wet periods in the Xijiang River basin, South China
}

\author{
T. Fischer ${ }^{1,2}$, M. Gemmer ${ }^{1,2}$, B. Su ${ }^{1,3}$, and T. Scholten ${ }^{2}$ \\ ${ }^{1}$ National Climate Center of the China Meteorological Administration, Beijing, China \\ ${ }^{2}$ Department of Geosciences, University of Tübingen, Tübingen, Germany \\ ${ }^{3}$ Nanjing University of Information, Science and Technology, Nanjing, China \\ Correspondence to: T. Fischer (tom.fischer8@gmx.de) and B.Su (subd@cma.gov.cn)
}

Received: 11 July 2012 - Published in Hydrol. Earth Syst. Sci. Discuss.: 19 September 2012

Revised: 24 November 2012 - Accepted: 22 December 2012 - Published: 17 January 2013

\begin{abstract}
In this study, hydrological long-term dry and wet periods are analyzed for the Xijiang River basin in South China. Daily precipitation data of 118 stations and data on daily discharge at Gaoyao hydrological station at the mouth of the Xijiang River for the period 1961-2007 are used. At a 24-month timescale, the standardized precipitation index (SPI-24) for the six sub-basins of the Xijiang River and the standardized discharge index (SDI-24) for Gaoyao station are applied. The monthly values of the SPI-24 averaged for the Xijiang River basin correlate highly with the monthly values of the SDI-24. Distinct long-term dry and wet sequences can
\end{abstract} be detected.

The principal component analysis is applied and shows spatial disparities in dry and wet periods for the six subbasins. The correlation between the SPI-24 of the six subbasins and the first principal component score shows that $67 \%$ of the variability within the sub-basins can be explained by dry and wet periods in the east of the Xijiang River basin. The spatial dipole conditions (second and third principal component) explain spatiotemporal disparities in the variability of dry and wet periods. All sub-basins contribute to hydrological dry periods, while mainly the northeastern sub-basins cause wet periods in the Xijiang River. We can also conclude that long-term dry events are larger in spatial extent and cover all sub-basins while long-term wet events are regional phenomena.

A spectral analysis is applied for the SPI-24 and the SDI24. The results show significant peaks in periodicities of 11-14.7 yr, 2.8 yr, 3.4-3.7 yr, and 6.3-7.3 yr. The same periodic cycles can be found in the SPI-24 of the six sub-basins but with some variability in the mean magnitude. A wavelet analysis shows that significant periodicities have been stable over time since the 1980s. Extrapolations of the reconstructed SPI-24 and SDI-24 represent the continuation of observed significant periodicities at given magnitudes until 2030. The projected hydrological long-term dry and wet periods can be used for planning purposes in water resources management. The applied methodologies prove to be able to identify spatial disparities, and to detect significant periodicities in hydrological long-term dry and wet periods in the Xijiang River basin.

\section{Introduction}

Decadal sequences of wet and dry years are historically documented for China, including the Huanghe (Yellow) River, the Yangtze River, and the Zhujiang (Pearl) River. Spatiotemporal changes in hydrological dry and wet patterns have been observed for large areas in China for the past 50$60 \mathrm{yr}$ since the meteorological and hydrological observation network has been extended. China is influenced by complex atmospheric circulation regimes that result in diverse precipitation patterns. These cause more frequent meteorological weather risks such as extreme droughts or serious floods than recorded in other parts of the world (Bordi et al., 2004a). A significant share of the global economic losses due to floods in the last decades has been recorded in China. According to the Munich Reinsurance Company (Berz and Kron, 2004), the floods on the Yangtze and Songhua rivers in 1998 and the 1996 floods on the Yangtze, Huanghe and Huaihe rivers caused material damages of 30.7 billion USD 
and 24 billion USD, respectively (nominal 1998 and 1996 price level). Droughts in the north, northeast, and southwest of China in 2009 have caused direct economic losses of about 18 billion USD.

Regional climate characteristics and the spatiotemporal variation of dry and wet periods in China have been described nationally (Zhai et al., 2010a, b), regionally (Bordi et al., 2003, 2004a; Zhai and Qi, 2009), and on basin scales (Zhang et al., 2005; Gemmer et al., 2008; Fischer et al., 2011, 2012, 2013). For China, the highest number of articles on observed changes in precipitation and river discharge are available for the Yangtze and the Yellow River. For example, Zhai et al. (2010b) analyzed changes from wet to more dry conditions and their impacts on the stream flow in the western regions of the Yellow and Yangtze rivers in the past $50 \mathrm{yr}$. Liu et al. (2011) projected an increase in spring/summer precipitation and its corresponding stream flow of the Yellow River for the 21 st century. In the past few years, more literature on these topics has been made available for the Zhujiang and Xijiang rivers.

The Xijiang River basin is located in subtropical South China. It is the major tributary of the Zhujiang River basin, the third largest river basin in China, and has a population of more than 100 million. The population and industrialization have been increasing in recent decades. Thus the damage potential resulting from extreme climate events and other natural disasters has risen (Feng et al., 2007; Fischer et al., 2011, 2012, 2013; Gemmer et al., 2011). Changes in precipitation and discharge in the Xijiang River basin with its tributaries are an important field of study for understanding their interaction and consequences.

As many other large rivers in China, the Xijiang River as part of the Zhujiang River basin is characterized by dams. The total storage capacity of reservoirs in the entire Zhujiang River basin had reached $65 \mathrm{~km}^{3}$ by 2005 , which accounts for $23 \%$ of the annual water discharge of the river (Dai et al., 2008). Annual water discharge is mainly influenced by variability in precipitation, and the construction of reservoirs/dams in the Zhujiang River basin had little influence on water discharge (Zhang et al., 2008).

Precipitation variability has therefore a high impact on water discharge in the Xijiang River. Recent findings on precipitation trends, climate extremes, and change points (Fischer et al., 2011, 2012) suggest that the hydrology in the Xijiang River basin has also changed. Xu et al. (2010) indicated that annual discharge of the Zhujiang River correlates well with basin-averaged precipitation. However, Gemmer et al. (2011) have observed increasing tendencies to dryer conditions and stronger precipitation intensities for the entire Zhujiang River basin from 1961 to 2007. Fischer et al. (2011) have observed increasing numbers for dry days, and Zhang et al. (2009) confirmed a tendency to drier conditions in the west of the basin. Another study suggests that the Zhujiang River basin has the largest human footprint of the 10 largest river basins in South and East Asia (Varis et al., 2012). Observations in climatological and hydrological time series show spatiotemporal changes of stream flow in the past $50 \mathrm{yr}$, mostly on annual scale. The characteristics and frequencies of long-term dry and wet periods in the Xijiang River basin have yet to be detected. Most of the studies mentioned above employed standard methods for assessing spatiotemporal changes in precipitation, in discharge, and in their trends, e.g. the standardized precipitation index, the aridity index, and nonparametric trend tests.

The main interest of this study is to evaluate changes in long-term precipitation pattern and their hydrological impact on the Xijiang River. The characteristics of hydrological long-term dry and wet periods are therefore analyzed in this manuscript. In previous studies, Bordi et al. (2003, 2004a, b, 2007) and Subash et al. (2011) applied the standardized precipitation index, the principal component analysis, and the power spectrum including the Morlet wavelet transform to assess the climatic conditions of a certain area, to capture pattern of co-variability, and to predict significant cycles of dry and wet periods. Combining these methods, we put our focus on the fluctuations in long-term dry and wet sequences of the past and the near future (1961-2030) in the Xijiang River basin. Therefore, we apply the standardized precipitation index (SPI), which is recommended by the World Meteorological Organization (WMO) to characterize wet and dry periods (Klein Tank et al., 2009). Alongside, the standardized discharge index (SDI) is applied to characterize dry and wet periods in river discharge. This will allow identifying how precipitation patterns influence the discharge of the river. The time series of the SPI and SDI are extrapolated in order to detect indications on dry and wet periods until 2030. This will be important information for water management and the design of adaptation measures.

In the following chapter, we first introduce the regional settings, the data we obtained and generated, and the methodologies we applied. The methodologies include the calculation of the SPI and SDI and the analysis of their principal components to identify regions with common climate variability. In Sect. 2, the power spectrum and the wavelet transform are applied to determine periodic cycles and to extrapolate the time series until 2030. In Sect. 3, the results are delivered for dry and wet periods in the Xijiang River basin and its six sub-basins. Finally, the findings are discussed and concluded in Sect. 4.

\section{Regional settings, data, and methods}

\subsection{Regional settings}

The Zhujiang River basin in subtropical South China (Fig. 1) covers an area of approximately $450000 \mathrm{~km}^{2}$ with a population of more than 160 million. The region is one of the economically most prosperous areas of China and has very high development rates. Its GDP per capita accounts for more than 


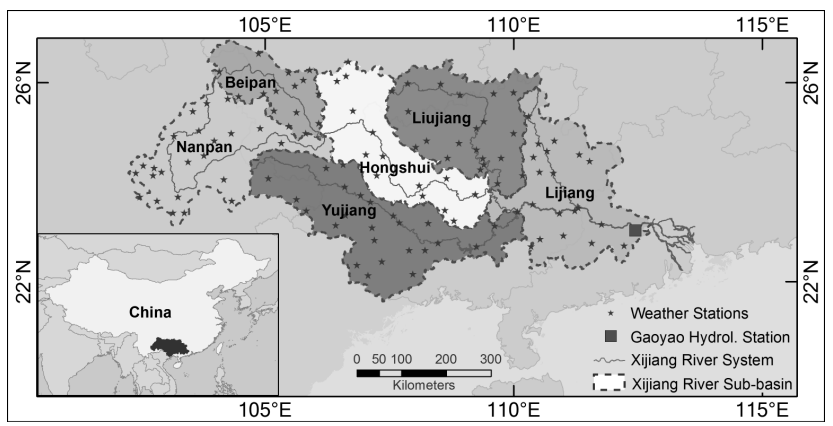

Fig. 1. Location of the river system, the six sub-basins, and the meteorological and hydrological stations in the Xijiang River basin in South China.

40000 CNY per year, which is one of China's highest rates (National Bureau of Statistics of China: www.stats.gov.cn). Since the 1950s, approximately 9000 dams with a reservoir storage capacity of $65 \mathrm{~km}^{3}$ have been constructed (Dai et al., 2008; Waterpub, 2012). In 2008, the Longtan Dam, China's third largest hydropower dam with an estimated capacity of $4.9 \mathrm{GW}$, started operating in the upper reaches of the Hongshui River (China Daily, 2008).

The Xijiang (west) River is the largest tributary of the Zhujiang River and accounts for $78 \%$ of the total drainage area of the Zhujiang River basin. The daily discharge of the Xijiang River is observed at Gaoyao hydrological station. In this study, the Xijiang River basin is divided into its six subbasins (Beipan, Nanpan, Yujiang, Hongshui, Liujiang, and Lijiang; see Fig. 1) in order to achieve a high level of spatial differentiation. Due to the availability of discharge data at Gaoyao and the high importance in the Zhujiang River basin, the Xijiang River basin and its six sub-basins are examined on their hydrological long-term dry and wet periods.

\subsection{Data}

Daily precipitation data of 118 weather stations in the Xijiang River basin (Fig. 1) for the period 1961-2007 and daily average discharge data of the hydrological station at Gaoyao on the Xijiang River for the period 1961-2006 are used. The National Meteorological Information Center (NMIC) of the China Meteorological Administration (CMA) provided the datasets. Each dataset was controlled on quality by the NMIC (Qian and Lin, 2005). The NMIC checked the data on homogeneity using the departure accumulation method (Buishand, 1982). Less than 0.1 percent of data gaps appear in daily precipitation records.

\subsection{Methods}

\subsubsection{Standardized precipitation and discharge indices (SPI \& SDI)}

At first, the total precipitation for the Xijiang River basin and separately for its six sub-basins (Fig. 1) is calculated on a weighted area approach using the Thiessen polygon method. This method is a common approach for modelling the spatial distribution of rainfall based on station observations (Jiang et al., 2007). A Thiessen polygon is formed around each meteorological station by first creating lines to the nearest neighbours. These lines are then bisected with perpendiculars that join either another perpendicular or the border of a sub-basin/basin to form the polygons. Each polygonal area is recalculated and then displayed as the percentage of the total area of the sub-basin/basin. For each station, the precipitation is multiplied with the respective percentage of its Thiessen polygon. The calculations of all polygons inside a sub-basin/basin are summed up to represent the total precipitation of the respective sub-basin/basin. In this study, the total precipitation of each sub-basin/basin is used to calculate the standardized precipitation index (SPI) for the six sub-basins and the entire Xijiang River basin.

The SPI is calculated with the statistical software R to quantify dry and wet periods (McKee et al., 1993). The SPI is a meteorological index using monthly precipitation data (Mishra and Singh, 2010). Comprehensive descriptions on the SPI and its application in China are available, e.g. from Bordi et al. (2004a), Zhang et al. (2009), Zhai et al. (2010a, b), and Zhao et al. (2012). The SPI is calculated for the weighted area-averaged monthly precipitation data and computed by fitting the two-parameter gamma distribution to the frequency distribution of the precipitation summed to a 24 month timescale (SPI-24). Here, the 24-month scale is suitable for the determination of hydrological dry and wet periods (Bordi et al., 2004a).

The standardized discharge index (SDI) is calculated correspondingly to the SPI. The same approach and distribution function (two-parameter gamma distribution) is applied. The SDI contains monthly discharge data and expresses hydrological excess or deficit availability of water. McKee et al. (1993) suggested the application of the SPI procedure to other water variables, such as observed discharge data. Hence, the method can be derived from McKee et al. (1993), Nalbantis and Tsakiris (2009), and Mishra and Singh (2010), although the respective terminology and input data vary in each of the manuscripts. To our best knowledge, the SDI has not been applied in the Xijiang River basin before. In this study, the SDI is calculated for monthly averaged discharge data at a 24-month scale (SDI-24).

In our analyses, we partially consider the categories of the SPI/SDI values according to Lloyd-Hughes and Saunders (2002), who defined the values at -1.00 to -1.49 as moderately dry $(-1.50$ to -1.99 as severely dry, and -2 or 
less as extremely dry), and the values at 1.00 to 1.49 as moderately wet (1.50 to 1.99 as severely wet, and 2 or more as extremely wet). As we use the averages of total precipitation (for Xijiang and its six sub-basins), lower SPI values occur than if single station data would have been used such as for the SDI. Hence, the magnitudes of dry and wet categories in the SPI of the sub-basins are not comparable with those of the entire basin (and the SDI).

\subsubsection{Principal component analysis}

The principal component analysis (PCA) is broadly used for identifying patterns in climate data and for highlighting their similarities and differences (Santos et al., 2011). Bordi et al. (2003, 2004a, b, 2007) and Zhao et al. (2012) describe the use and background of the PCA in detail. In this study, we calculate the PCA with the statistical software R and use the PCA for identifying the spatial co-variability of the SPI24 in the six sub-basins of the Xijiang River. A set of linearly independent spatial patterns (loadings) is generated, which describes the correlations with the specific principal components (PC). We analyze the spatial homogeneity or heterogeneity of dry and wet periods in the Xijiang River's subbasins with the results for the PCA's loading patterns. The results are used to underline the regional disparities and interrelations of dry and wet periods at the sub-basin scale.

\subsubsection{Power spectrum and continuous wavelet analysis}

The fast Fourier transform is used to generate the power spectrum of the signal in the monthly time series (Schönwiese, 2006; Wilks, 2006). We determine significant periodicities that are embedded in the time series based on the amplitude of the corresponding signal. Similarly, a continuous wavelet transform is used to break up the signal into shifted and scaled versions of the original wavelet by decomposing a time series into a time/frequency space (Torrence and Compo, 1998). In this study, we apply the Morlet wavelet, which is the most commonly used continuous wavelet transform for visualizing the amplitudes in the time/frequency space. The calculations are made with the related packages of the statistical software R. The significance of the amplitudes of the periodicities is based on the $90 \%$ confidence level that is calculated with the Chi-squared distribution at four degrees of freedom (Becker et al., 2008; Bordi et al., 2004a). The results are used for detecting periodicities and their changes in time (i.e. time-frequency relationships) in climatological datasets. Gao et al. (2010) used the continuous wavelet transform likewise in order to assess the fluctuation of monthly observed and projected average stream flows (return periods of extremes) in the Huaihe River basin in China. Becker et al. (2008) determined quasi-periodicities of extreme precipitation events in the Yangtze River basin by employing the continuous wavelet analysis.

\subsubsection{Extrapolation}

The time series for the SPI-24 and SDI-24 are extrapolated from 2007 to 2030 in order to show dry and wet periods for the next two decades, using the parameterized software "AutoSignal". We apply the fast Fourier transform to the significant periodicities that have been identified in the power spectrum analysis. We estimate future monthly values by extrapolating the observed time series as applied by Bordi et al. (2004a). This estimation is based on the assumption that the significant periods are stable in time; i.e. the periodicity is similar for the following two decades (Becker et al., 2008). We expect that there will be no major changes in the frequency of dry and wet periods (i.e. stable periodicities) in the near future (until 2030), as previous studies (e.g. Gemmer et al., 2011; Fischer et al., 2011) did find few significant trends only in observed monthly precipitation pattern. In order to characterize the reliability of this assumption, we investigate the stability of significant periods in the wavelet analyses.

\section{Results}

\subsection{Relationship between precipitation and discharge}

We follow the principle that a river basin as a hydrological unit is drained by a river of first order and its tributaries and that most precipitation over the land area of the river basin will result in surface runoff that accumulates in the main river system. Hence, the annual precipitation over the river basin can be compared with the discharge at the point where it exits the defined river basin's boundary. Figure 2 shows the time series of the area-averaged annual precipitation in the Xijiang River basin and the mean annual discharge at Gaoyao hydrological station from 1961 to 2006 . The annual average precipitation is about $1350 \mathrm{~mm}$, and the inter-annual variability is $10 \%$ according to the coefficient of variation. Two distinct minima in annual precipitation (below $1100 \mathrm{~mm}$ ) can be observed for 1963 and 1989, respectively. A maximum in annual precipitation (above $1700 \mathrm{~mm}$ ) occurred in 1994.

The annual average discharge from 1961 to 2006 is $7000 \mathrm{~m}^{3} \mathrm{~s}^{-1}$ (Fig. 2). The inter-annual variability is $19 \%$. Two minima in discharge (below $5000 \mathrm{~m}^{3} \mathrm{~s}^{-1}$ ) appeared in 1963 and 1989, consecutively with the minima in precipitation. Two maxima (above $10000 \mathrm{~m}^{3} \mathrm{~s}^{-1}$ ) can be observed in 1968 and 1994. A strong correlation (0.88) is found for the monthly area-averaged precipitation and monthly discharge at Gaoyao station from 1961 to 2006.

Figure 3 shows the average distribution of monthly precipitation in the Xijiang River basin and the average distribution of monthly discharge at Gaoyao hydrological station from 1961-2006. June shows the highest monthly precipitation with nearly $250 \mathrm{~mm}$. The highest monthly discharge can be measured in July with nearly $16000 \mathrm{~m}^{3} \mathrm{~s}^{-1}$. We can identify a distinct seasonality with a noticeable dry period 


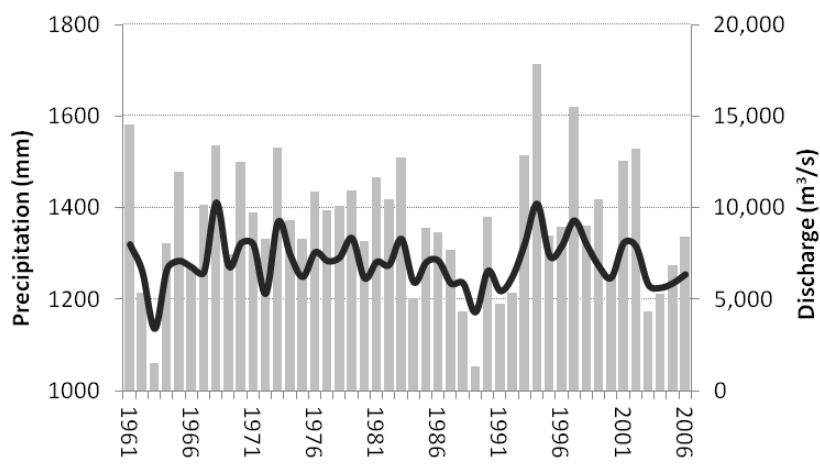

Fig. 2. Annual precipitation (grey bars) in the Xijiang River basin and annual discharge (black line) at Gaoyao hydrological station 1961-2006.

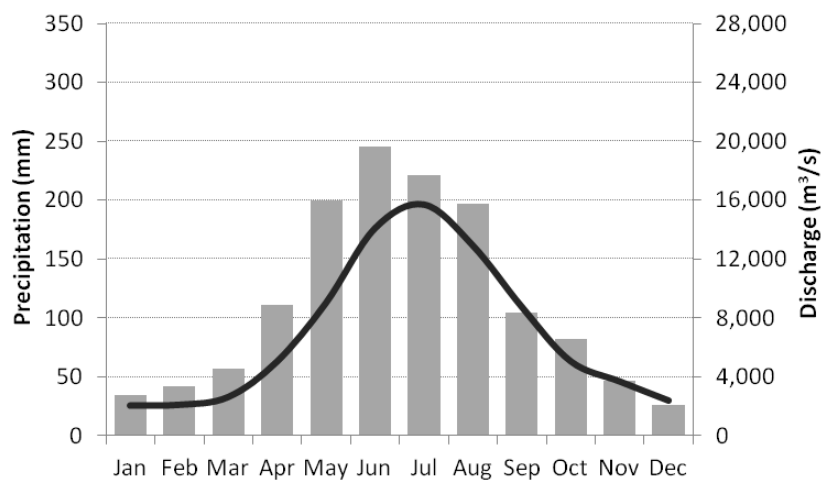

Fig. 3. Average monthly precipitation (grey bars) in the Xijiang River basin and average monthly discharge (black line) at Gaoyao hydrological station 1961-2006.

from November to March, when monthly precipitation is less than $50 \mathrm{~mm}$ and monthly discharge can account for less than $4000 \mathrm{~m}^{3} \mathrm{~s}^{-1}$. Based on the coefficient of variation, the highest inner-annual variability of monthly precipitation can be observed in December with $69 \%$ and the highest monthly variability of discharge occurs in March (64\%). The high percentages are mainly due to the low magnitudes of precipitation and discharge in these months.

The monthly precipitation and discharge in 1963 and 1994 are shown in Fig. 4. As compared to the long-term average, much less (more) precipitation and discharge was observed in 1963 (1994), especially in summer (May to August). Precipitation and discharge were $40 \%$ to $85 \%$ below average in 1963 and $30 \%$ to $100 \%$ above average in 1994 .

The time series show a strong correlation between the monthly area-averaged precipitation and monthly discharge in the Xijiang River basin. Based on the monsoon climate in the research area, the inner-annual variability of precipitation and discharge corresponds as expected. It is of high interest whether the inter-annual variability of precipitation and discharge can be linked to typical hydrological long-term dry and wet periods. Therefore, the magnitude and periodicity of

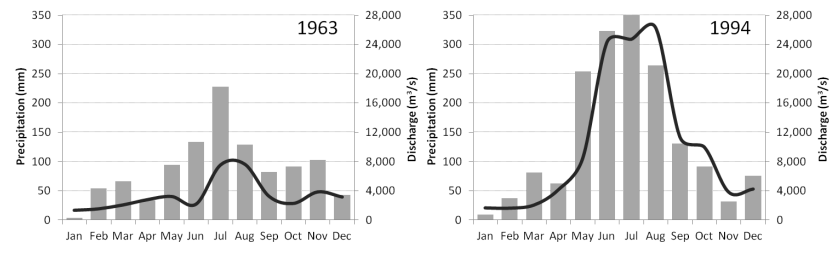

Fig. 4. Average monthly precipitation (grey bars) in the Xijiang River basin and average monthly discharge (black line) at Gaoyao hydrological station in 1963 (left) and 1994 (right).
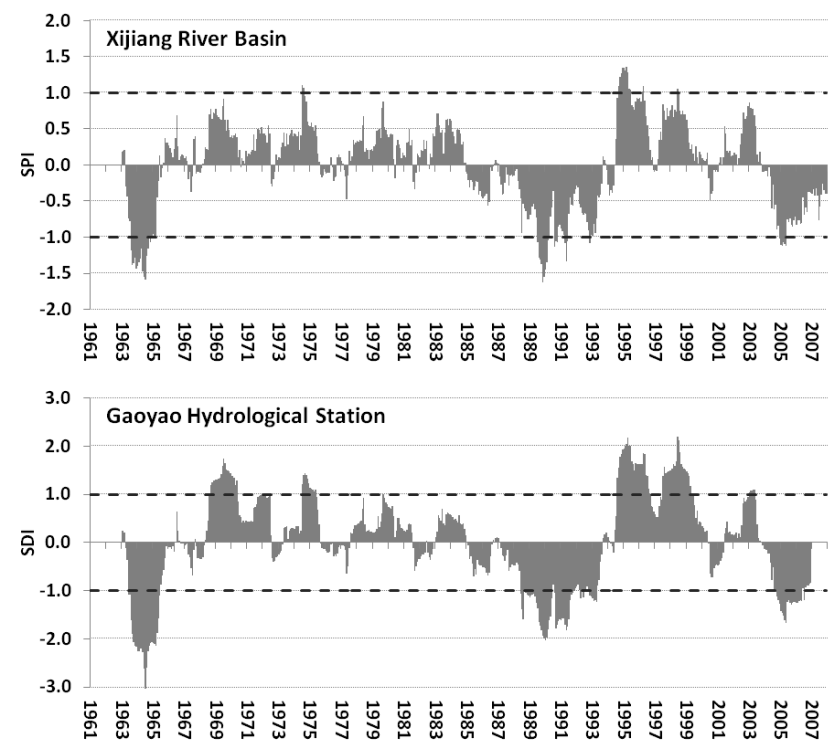

Fig. 5. SPI-24 of the Xijiang River basin (upper panel) and the SDI24 of Gaoyao hydrological station (lower panel).

such long-term dry and wet events and their inter-relation are analyzed in the following.

\subsection{Relationship between SPI-24 and SDI-24}

The SPI-24 for the entire Xijiang River basin and the SDI24 for Gaoyao hydrological station are shown in Fig. 5. The magnitude in the categories of the SPI-24 cannot be compared with the magnitude of the categories of the SDI-24 as the SPI-24 has been averaged from 118 meteorological stations while the SDI-24 results from one hydrological station. Nevertheless, the categories for wet and dry conditions can be compared.

The SPI-24 (Fig. 5 upper panel) shows that wet conditions (SPI category $>1$ ) prevailed for about $20 \mathrm{yr}$ after a dry period (SPI values $<-1$ ) had ended in 1965. Dry conditions at different magnitudes characterize the period of 1985-1995. A wet period started after 1995 and remained nearly uninterrupted for $10 \mathrm{yr}$. After 2004, dry conditions prevailed in the Xijiang River basin. The most distinct peaks in wet periods occurred around 1974 and 1995. Peaks in dry periods occurred around 1964, 1990, and 2005. 
Table 1. Duration and magnitude of peak events in dry (SPI $<-1$ ) and wet (SPI $>1$ ) periods in the six sub-basins of the Xijiang River basin, the entire basin (Xijiang), and at Gaoyao hydrological station (SDI <-1, SDI > 1), 1963-2006.

\begin{tabular}{|c|c|c|c|c|c|c|c|c|c|}
\hline \multirow[b]{2}{*}{ Peak Event in: } & \multirow[b]{2}{*}{ Period } & \multicolumn{8}{|c|}{ Duration (months) } \\
\hline & & Nanpan & Beipan & Hongshui & Liujiang & Yujiang & Lijiang & Xijiang & Gaoyao \\
\hline \multirow{5}{*}{$\begin{array}{l}\text { Dry period } \\
(<-1)\end{array}$} & 1963-1965 & 14 & 9 & 16 & 20 & 20 & 19 & 18 & 25 \\
\hline & 1988-1990 & 17 & 14 & 11 & 8 & 16 & 3 & 10 & 25 \\
\hline & 1990-1992 & 8 & 11 & 3 & 4 & 5 & 22 & 7 & 20 \\
\hline & 2004-2006 & 2 & 27 & 6 & 3 & 6 & 8 & 6 & 22 \\
\hline & event sum & 41 & 61 & 36 & 35 & 47 & 52 & 41 & 92 \\
\hline \multirow{6}{*}{$\begin{array}{l}\text { Wet period } \\
(>1)\end{array}$} & $1968-1970$ & 0 & 13 & 12 & 7 & 0 & 0 & 0 & 21 \\
\hline & $1974 / 1975$ & 3 & 0 & 2 & 2 & 8 & 12 & 2 & 11 \\
\hline & 1994-1996 & 0 & 0 & 13 & 20 & 5 & 21 & 12 & 26 \\
\hline & $1997 / 1998$ & 0 & 0 & 2 & 3 & 2 & 15 & 1 & 23 \\
\hline & event sum & 3 & 13 & 29 & 32 & 15 & 48 & 15 & 81 \\
\hline & & \multicolumn{8}{|c|}{ Mean Magnitude (sum of monthly SPI values) } \\
\hline Peak Event in: & Period & Nanpan & Beipan & Hongshui & Liujiang & Yujiang & Lijiang & Xijiang & Gaoyao \\
\hline \multirow{5}{*}{$\begin{array}{l}\text { Dry period } \\
(<-1)\end{array}$} & 1963-1965 & -21.4 & -11.3 & -23.1 & -25.1 & -26.8 & -24.7 & -23.0 & -51.0 \\
\hline & 1988-1990 & -23.0 & -25.8 & -15.7 & -9.5 & -21.1 & -3.4 & -13.1 & -35.7 \\
\hline & 1990-1992 & -8.5 & -20.1 & -3.2 & -4.6 & -6.0 & -30.5 & -7.8 & -29.3 \\
\hline & 2004-2006 & -3.4 & -33.4 & -6.4 & -3.1 & -6.3 & -10.2 & -6.5 & -29.5 \\
\hline & event sum & -56.3 & -90.6 & -48.5 & -42.4 & -60.2 & -68.8 & -50.4 & -145.5 \\
\hline \multirow{5}{*}{$\begin{array}{l}\text { Wet period } \\
(>1)\end{array}$} & 1968-1970 & 0.0 & 16.0 & 13.5 & 7.7 & 0.0 & 0.0 & 0.0 & 29.1 \\
\hline & $1974 / 1975$ & 3.3 & 0.0 & 2.3 & 2.1 & 9.2 & 14.0 & 2.2 & 13.5 \\
\hline & 1994-1996 & 0.0 & 0.0 & 20.0 & 35.2 & 5.3 & 28.0 & 14.4 & 43.8 \\
\hline & $1997 / 1998$ & 0.0 & 0.0 & 2.1 & 3.4 & 2.2 & 18.0 & 1.0 & 35.7 \\
\hline & event sum & 3.3 & 16.0 & 37.9 & 48.5 & 16.7 & 60.0 & 17.6 & 122.1 \\
\hline
\end{tabular}

Changes in the categories of the SDI-24 (Fig. 5 lower panel) occurred similarly to that in the SPI-24. The SDI24 takes the same chronological positive and negative course and shows the same peaks and durations of dry and wet periods as the SPI-24. The highest peak of dry conditions in the SPI-24 (around 1964) marks the most severe dry event in the SDI-24. The coefficient of correlation of the average SPI-24 and the SDI-24 is 0.94 .

The peak years in SPI-24/SDI-24 occur simultaneously with the maxima and minima in the annual precipitation and annual average discharge (Fig. 2). The SPI-24/SDI-24 reveals long-term dry and wet periods for the Xijiang River basin. The strong similarities imply a high impact of natural precipitation pattern on the discharge. This relationship can be spatially disaggregated and explained by investigating the SPI-24 of the six sub-basins.

The SPI-24 of the six sub-basins is illustrated in Fig. 6. Sequences of wet and dry periods vary in the sub-basins. In general, the SPI-24 of the sub-basins takes the same course as the averaged SPI-24 for the entire basin (Fig. 5). However, the wet conditions after 1965 are more distinct (1) in magnitude for the Beipan sub-basin (northwest) and (2) in duration for the Nanpan sub-basin (west). Beipan shows a higher magnitude in the dry event of the early 1990s, whereas dry conditions lasted longer in the Liujiang sub-basin (southeast).

Focusing on wet periods (SPI $>1$ ) and dry periods (SPI $<-1$ ), dry events appear simultaneously in all six sub-basins around 1965, 1990 and 2005. The dry event around 1986 appears in $50 \%$ of the sub-basins. Most of the wet periods appeared simultaneously in two to three of the sub-basins only (e.g. 1983, 2003). The wet event around 1975 occurred in five of the six sub-basins, but wet periods never appeared simultaneously in all of the six sub-basins. Figure 6 shows the spatial variability of dryness and wetness conditions. As can be seen, dry periods have a larger spatial extent than wet periods.

The correlation coefficient between the SPI-24 of each of the six sub-basins and the SDI-24 varies between 0.65 (Beipan) and 0.82 (both Hongshui and Yujiang). This suggests that each sub-basin has a considerable impact on the SDI-24 at Gaoyao hydrological station. However, some subbasins contribute higher to the discharge than others.

Conclusively, dry and wet periods in the SDI-24 can be profoundly explained by dry and wet conditions in the 

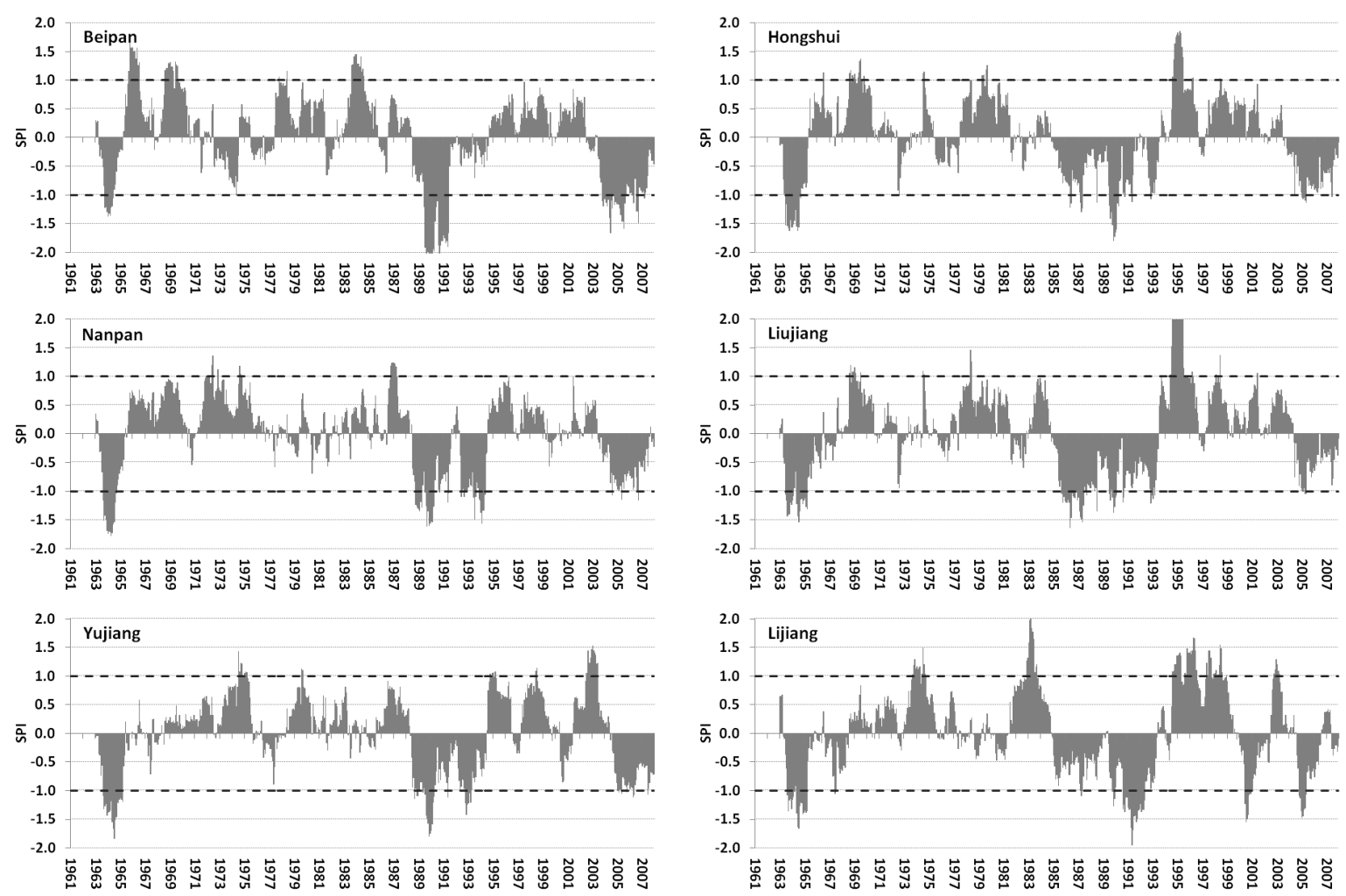

Fig. 6. SPI-24 of the six sub-basins in the Xijiang River basin.

SPI-24. We have identified distinct long-term dry and wet periods in the Xijiang River basin and the sub-basins that contribute most to the hydrological dry and wet conditions. We analyze their frequencies in the following sections in order to determine the temporal characteristics of dry and wet events and their changes.

\subsection{Peak dry and wet periods}

Frequencies of peaks in dry and wet events can be explained in different ways. In this study, the duration and magnitude of dry and wet periods are of highest interest. The duration of dry and wet events is scattered if the values fall below a given threshold (Mishra and Singh, 2010). We take the categories of "below -1 " and "above 1" in the SPI/SDI as thresholds, although the magnitudes in the SPI-24 and SDI-24 cannot be compared.

Four distinct dry events and four wet periods appear from 1963 to 2006 (Fig. 5). Distinct dry events occurred during 1963-1965, 1988-1990, 1990-1992, and 2004-2006. In summer 1990 , a relatively wet period of few months separates the two distinct dry events. The wet events (1968-1970, 1974/1975, 1994-1996, and 1997/1998) show regional disparities between the sub-basins; i.e. most events occur only in half of the sub-basins (Fig. 6).

Table 1 shows the duration (in months) and the mean magnitude (as sum of SPI-24 or SDI-24) of hydrological long term dry and wet periods according to the SPI-24 and SDI24 for values below -1 (dry event) and above 1 (wet event). Most of the dry periods can be detected simultaneously in the sub-basins, the entire Xijiang River basin, and Gaoyao hydrological station. Wet periods are regionally scattered. However, as can be seen, the dry period in the SDI-24 of 19631965 had the same duration as the dry period in 1988-1990, but was higher in magnitude. The dry period in 2004-2006 in SDI-24 ranks third both in duration and magnitude. The SPI24 corresponds likewise. The longest and highest wet period in the SDI-24 occurred in the 1990s. The period 1994-1996 shows the longest and highest wet events in both the SDI-24 and SPI-24.

Regarding each sub-basin's role in contributing to the intensity of the hydrological dry or wet periods at Gaoyao, each sub-basin contributed differently to each detected dry or wet event (Table 1). For example, the dry period of 19631965 occurred longer and more strongly in the eastern subbasins than in the west; hence the east contributed more to the long-lasting dry period at Gaoyao. In contrary, the long dry event at Gaoyao in 2004-2006 was strongly affected by a dry period in Beipan of more than two years. It can be seen that all sub-basins contributed differently to dry conditions, while proportionately the (north-)eastern sub-basins contribute more strongly to the wet conditions at Gaoyao. 


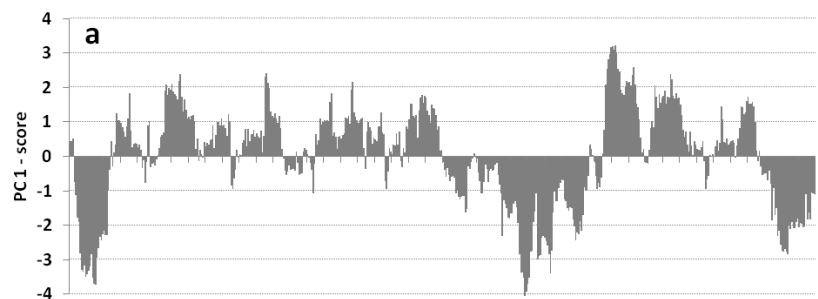

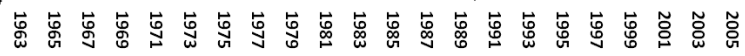
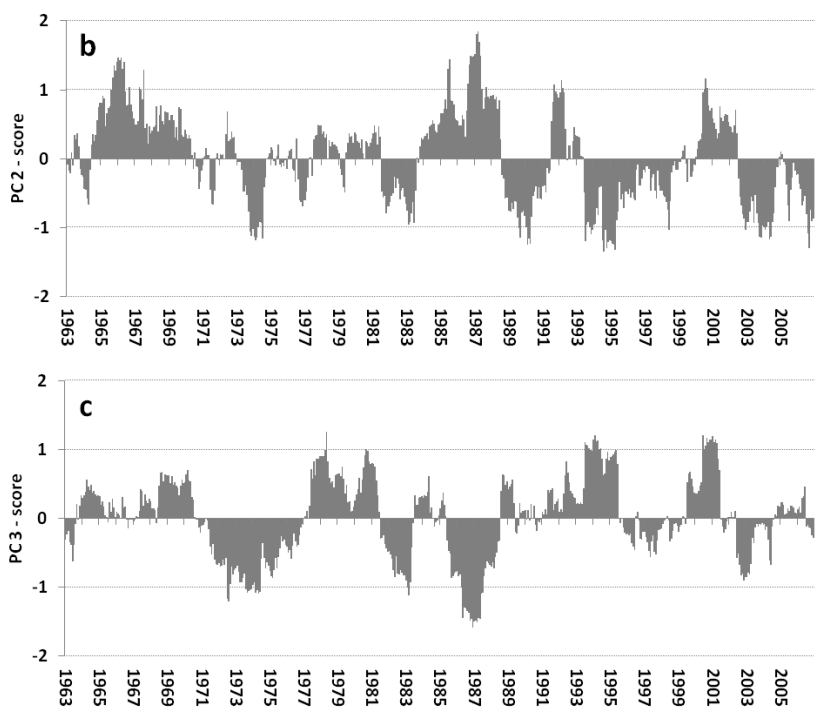

Fig. 7. PC scores of the SPI-24 in the Xijiang River basin.

The SPI-24 of the sub-basins of Xijiang River each has a certain share on the dry and wet periods at Gaoyao hydrological station. This finding will be further investigated and specified with the principal components analysis (PCA) in the following.

\subsection{Principal component analysis of SPI-24}

Principal component (PC) scores are analyzed in order to illustrate the spatiotemporal variability of the dry and wet periods in the Xijiang River basin. The PC scores of the SPI-24 are displayed in Fig. 7. The first three loadings explain $92 \%$ of the variance. PC-1 (Fig. 7a) explains $67 \%$ of the variance and shows multi-annual fluctuations. PC-2 shows a higher frequency of negative values and describes $14 \%$ of the variance (Fig. 7b), whereas PC-3 falls below $11 \%$ with balanced positive and negative values (Fig. 7c). As expected, the magnitude of all PC scores is highest in PC-1 given the high percentage. PC-3 shows a higher tendency to dry conditions (in magnitude and duration) than PC-2.

The loading pattern (linearly independent spatial pattern) of PC-1, PC-2, and PC-3 in each of the sub-basins is displayed in Fig. 8. In Fig. 8a, the correlation between each subbasin's PC-1 loading and the averaged PC-1 loading shows highest values in Liujiang (0.44) and slightly lower values for the other five sub-basins with a decrease from northeast
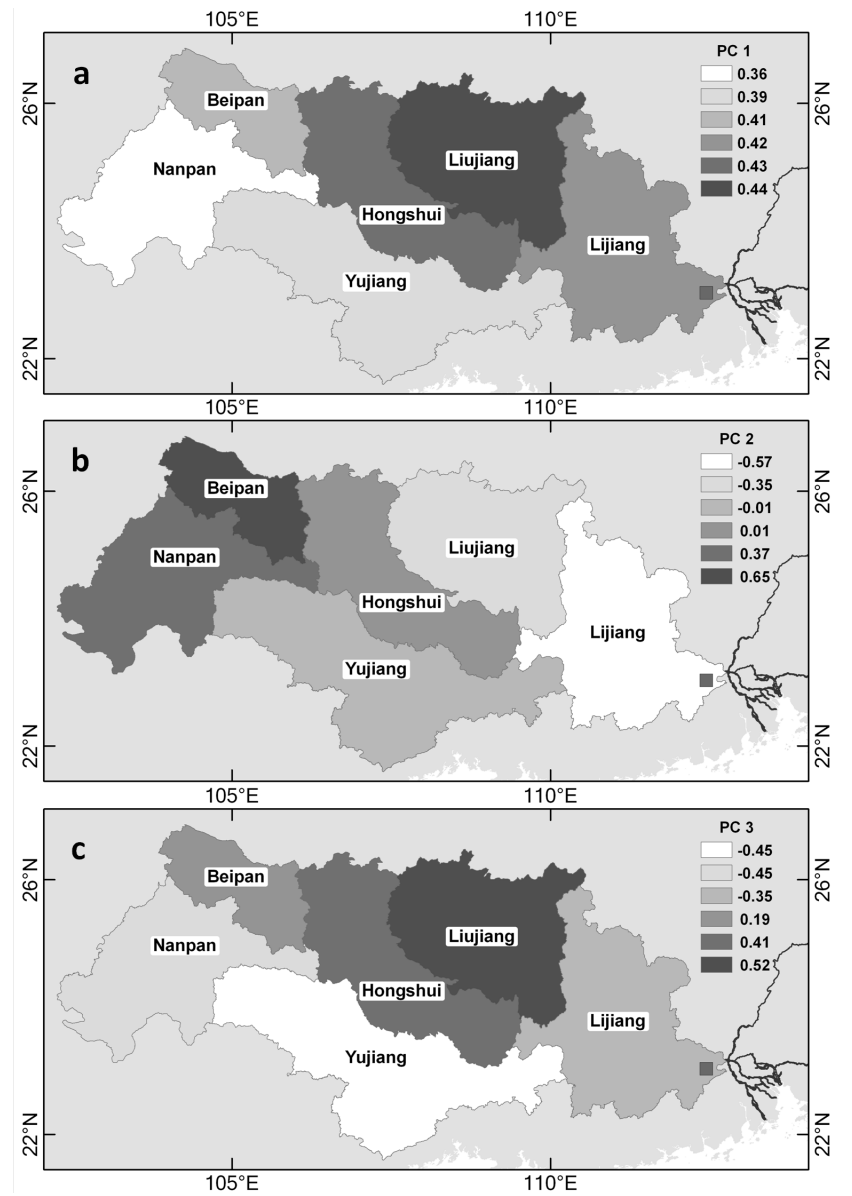

Fig. 8. Loading pattern of PC-1 (a), PC-2 (b), and PC-3 (c) in the six sub-basins of the Xijiang River basin.
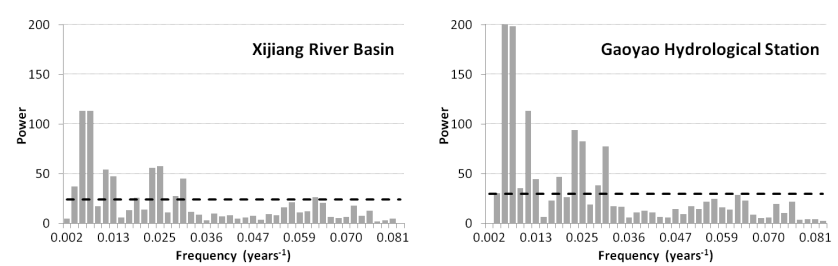

Fig. 9. Spectral analysis of the SPI-24 (left panel) and SDI-24 (right panel); the dashed line corresponds to the $90 \%$ confidence interval of significant periods.

to southwest. Hence, as the loading values of PC-1 are quite similar for all sub-basins, around $67 \%$ of the variance in the SPI-24 is resulting from a homogeneous precipitation regime in the Xijiang River basin. The loading of PC-2 (Fig. 8b) is negative for three sub-basins in the east and positive in the west. PC-3 (Fig. 8c) also reflects a dipole pattern from south to north. These dipole conditions explain the opposing course of the sub-basin SPI-24 in some few years (especially in the mid-1980s) and the difference in magnitude in others. 

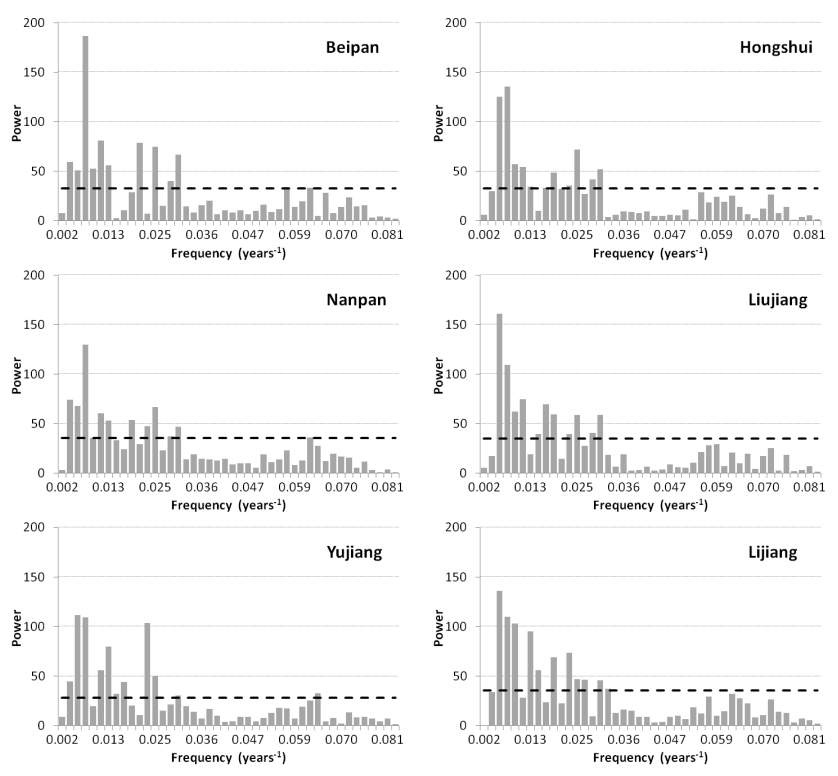

Fig. 10. Spectral analysis of the SPI-24 of the six sub-basins in the Xijiang River basin; the dashed line corresponds to the $90 \%$ confidence interval of significant periods.

The PCA's loading pattern describes a generally good spatial homogeneity of dry and wet periods in the Xijiang River basin. Spatially heterogeneous dry and wet periods in some years can be explained by these loading patterns. In the following, we investigate the periodicity of peak dry and wet periods.

\subsection{Periodicities of SPI-24 and SDI-24}

The results of the spectral analysis (Fig. 9) show similar peaks in the SPI-24 and the SDI-24. The highest peaks (power magnitude) in SPI-24 and SDI-24 are located between 0.006 and 0.008 representing significant frequencies (at the $90 \%$ confidence level) at $11-14.7 \mathrm{yr}$ periods. Lower peaks are found at frequencies of $2.8 \mathrm{yr}, 3.4-3.7 \mathrm{yr}$, and 6.3$7.3 \mathrm{yr}$. The magnitude of the peaks in SPI-24 and SDI-24 varies slightly. This underlines that dry and wet periods are subject to distinct periodic reoccurrence.

The results of the spectral analysis for the six sub-basins of the Xijiang River basin are shown in Fig. 10. All sub-basins show most significant (at the $90 \%$ confidence level) peaks at 11 and $14.7 \mathrm{yr}$ periods. In Beipan and Nanpan, the $11 \mathrm{yr}$ peak is much stronger. The $14.7 \mathrm{yr}$ period is the strongest of all periods in the other four sub-basins. Other peaks are similar to those for the SPI-24 and SDI-24. However, Yujiang is the only watershed with a distinct peak at $3.7 \mathrm{yr}$, which is nearly as high as that for the 11-14.7 yr period. Lower peaks for all sub-basins are found at frequencies of $2.8 \mathrm{yr}, 3.4-3.7 \mathrm{yr}$, and 6.3-7.3 yr. These periods highlight consistency with the periods in the SPI-24 of the entire Xijiang River basin and the
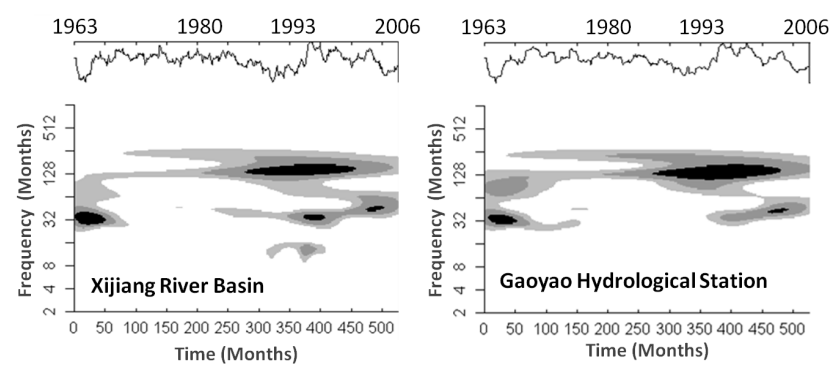

Fig. 11. Wavelet analysis of the SPI-24 (left panel) and the SDI24 (right panel) showing the low (grey) to high (black) significant amplitudes of the frequencies.

SDI-24 of Gaoyao hydrological station with some variation in magnitude.

Figure 11 shows the results of the wavelet analyses of the SPI-24 (entire Xijiang River basin) and the SDI-24. As can be seen, the significant periodicity in the SPI-24 and SDI-24 at $11-14.7 \mathrm{yr}$ frequency has been stable over time since the 1980s and has the highest amplitude (i.e. significance) in the 1980s and 1990s. The peak amplitude in the SPI-24 of 3.4$3.7 \mathrm{yr}$ frequency shifts slightly over time after the 1980s. It loses some significance in the late 1990s and shifts to slightly moderate amplitude.

As the PCA suggests spatial disparities in dry and wet periods, we analyze the wavelet pattern of the SPI-24 for the six sub-basins (Fig. 12). The 11-14.7 yr frequency appears for all sub-basins and is stable over time and in amplitude except for Yujiang. The latter is dominated by a frequency of $3.7 \mathrm{yr}$. The sub-basins of Beipan and Hongshui are dominated by the 11-14.7 yr frequency over the entire time series, whereas the frequency has slightly longer periods in Hongshui. The frequency of 3.4-3.7 yr is most persistent in Hongshui. The sub-basins located in the south and east (Yujiang and Lijiang) lack significant periodicities in the first decade of the time series. The frequency of $3.7 \mathrm{yr}$ in Beipan and Nanpan disappears in the 1960s, whereas it amplifies in Lijiang and Liujiang in the 1990s.

In the following, we extrapolate the significant peaks of the spectral analysis assuming that the periodicity of observed dry and wet periods will prevail in future.

\subsection{Extrapolation of SPI-24 and SDI-24}

Figure 13 shows the SPI-24 and SDI-24 extrapolated until 2030. The extrapolation of the SPI-24 (entire Xijiang River basin) is dominated by a significant short-term periodicity of 2.8 and 3.4-3.7 yr, respectively, that can be seen in the reconstructed frequency (black line from 1963 to 2006). The beginning of the extrapolation (from 2007 until 2014) shows a change from slightly wet to dry conditions. After 2014, the extrapolation points out an increase in SPI-24 values, which peak in a wet period in 2028. This wet period is followed by dry conditions. Likewise, the reconstructed frequency and 


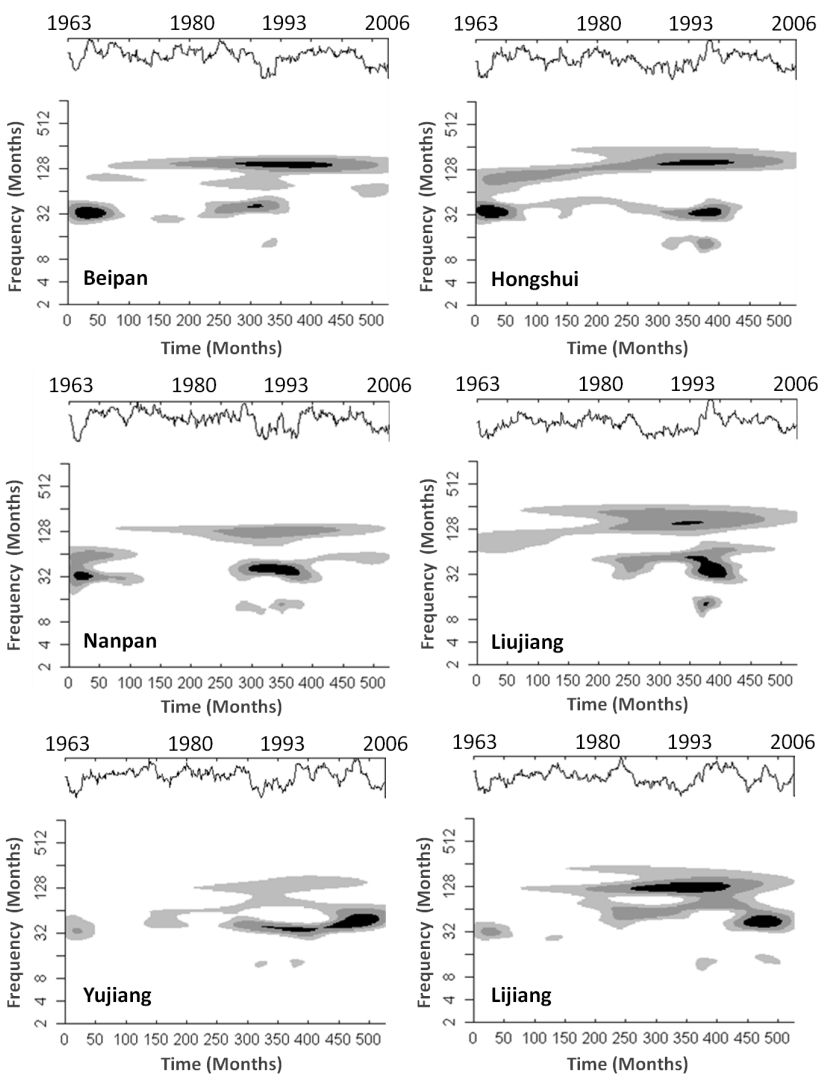

Fig. 12. Wavelet analysis of the SPI-24 of the six sub-basins in the Xijiang River basin showing the low (grey) to high (black) significant amplitudes of the frequencies.

the extrapolation of the SDI-24 show a similar course as the SPI-24.

The significant periodicities in the power spectrum dominate the reconstructed frequency for each of the six subbasins (Fig. 14). The extrapolation shows a continuation of the main periodicities. Distinct spatial disparities in the extrapolation (and reconstruction) of the SPI-24 can be seen. The period 2007-2008 is highlighted by a shift from dry to normal conditions in the sub-basins. The only exception is the Beipan sub-basin, which shows an aggravation of dry conditions towards an extreme dry period starting in 2008 . Based on the periodicity for each sub-basin, the course of the SPI-24 shows different magnitudes and durations in the extrapolations. A $3.7 \mathrm{yr}$ periodicity is obvious in Yujiang and Hongshui, whereas the extrapolation for the other sub-basins is dominated by longer periods.

\section{Discussion and conclusions}

The main interest of this study was to evaluate the impact of long-term precipitation pattern on the discharge of the $\mathrm{Xi}$ jiang River. Therefore, the characteristics of long-term hydrological dry and wet periods were analyzed. It can be
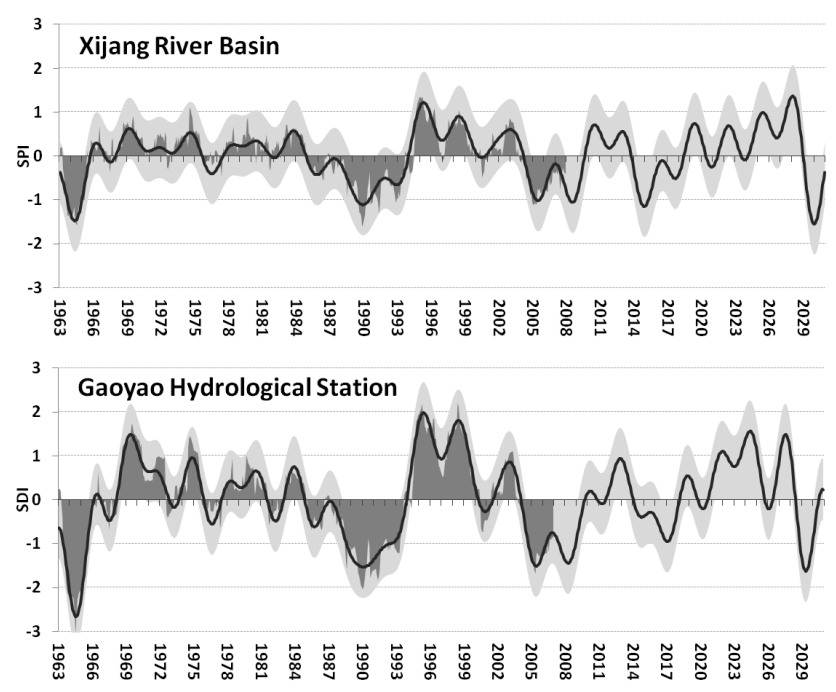

Fig. 13. Observed (dark grey shadings) and reconstructed time series (black line; confidence interval = light grey shading) plus extrapolation (starting in 2007) of the SPI-24 (upper panel) and SDI24 (lower panel) of the Xijiang River basin and Gaoyao hydrological station, 1963-2030.

concluded that the discharge of the Xijiang River (SDI-24) is a direct response to the area weighted SPI-24 of the entire Xijiang River basin. Hence, changes in precipitation are directly responsible for changes in discharge. This is in line with the findings of Zhang et al. (2008), who concluded that long-term changes of annual water discharge are mainly controlled by precipitation variation, while the construction of reservoirs/dams has made little influence on water discharge in the Zhujiang River basin. We can also conclude that each sub-basin has an individually strong impact on the SDI-24 at Gaoyao hydrological station. Some sub-basins contribute to a higher degree to the discharge (correlation up to 0.82 ) than others.

With the calculation of the spatial interdependencies of the sub-basins using the PCA, it was possible to analyze that all sub-basins contribute to hydrological dry periods, while mainly the northeastern sub-basins cause wet periods at Gaoyao station. The western sub-basins have rather little influence in hydrological wet periods of the Xijiang River. We can also conclude that long-term dry events are larger in spatial extent, covering all sub-basins, than long-term wet events.

Distinct cycles of several years can be detected for dry and wet periods. Precipitation in the Xijiang River basin and the discharge of the Xijiang River are dominated by significant periodicities of 11-14.7 $\mathrm{yr}$ and significant cycles of shorter periodicity (2.8 yr, 3.4-3.7 yr, and 6.3-7.3 yr). Similar periodicities have been found for several other large river basins in East China (Bordi et al., 2003, 2004a), but also for the Elbe River basin and Sicily (Bordi et al., 2004b). Such similarities suggest that regional atmospheric circulation systems 

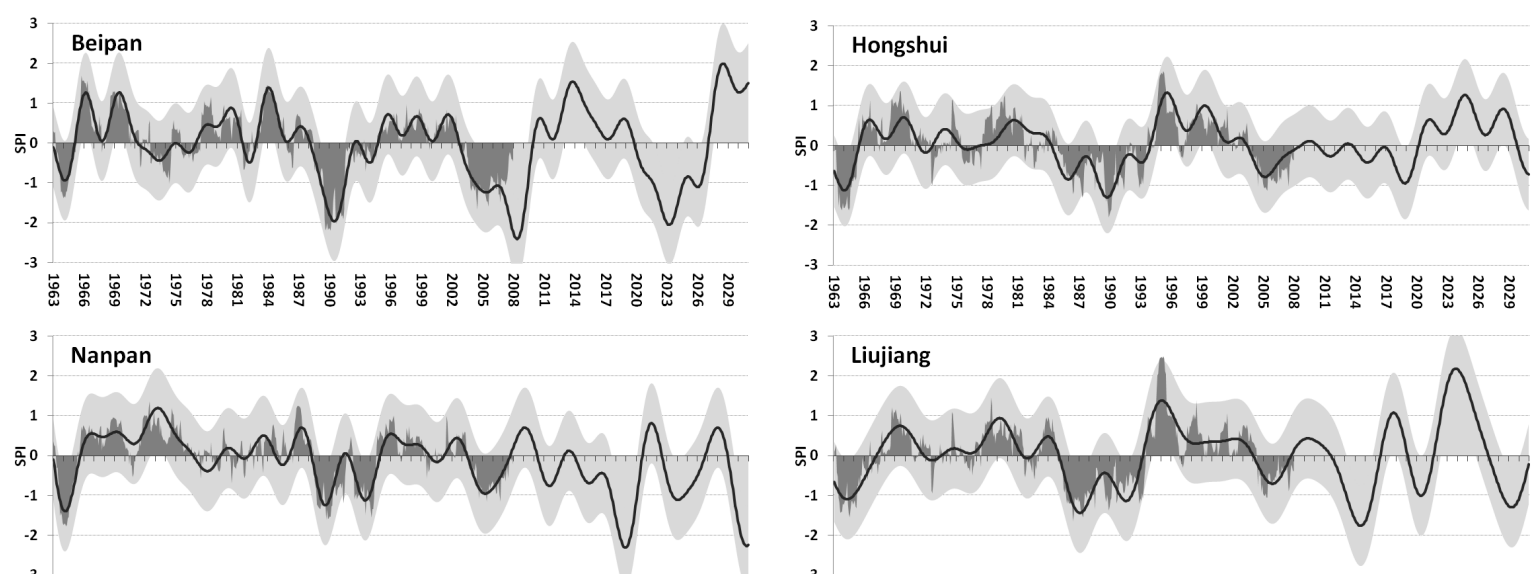

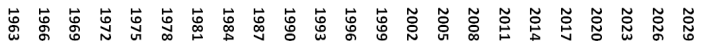

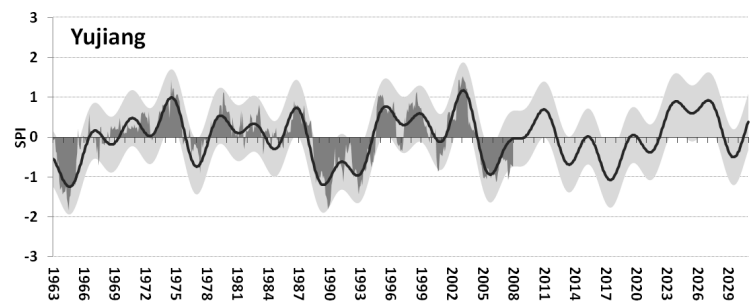

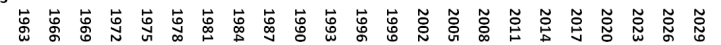

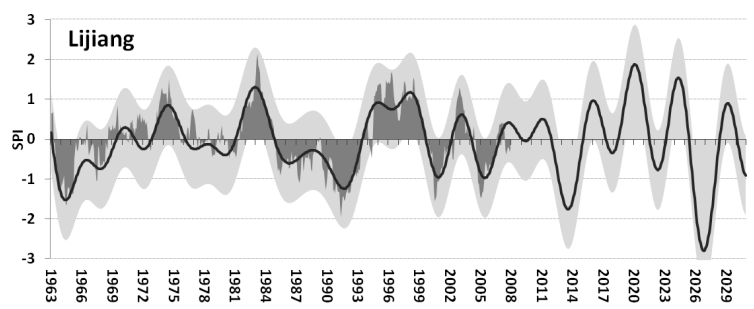

Fig. 14. Observed (dark grey shadings) and reconstructed time series (black line; confidence interval = light grey shading) plus extrapolation (starting in 2007) of the SPI-24 of the six sub-basins in the Xijiang River basin 1963-2030.

are inter-connected with the global atmospheric circulation and follow distinct climatic cycles. An 11-14.7 yr oscillation in precipitation is therefore the controlling force for the longterm hydrological status in the Xijiang River basin. Additionally, disparities in SPI-24 and periodicity can be observed for the sub-basins, which can be explained by regional disparities in annual and monthly precipitation pattern, with annual values decreasing from the east to the west of the river basin (Gemmer et al., 2011). Due to the strong correlation of the SPI-24 and the SDI-24, it can also be concluded that cycles in the SPI-24 are mainly responsible for cycles in the SDI24. In future, changes in the periodicities of the SPI-24 will alter the periodicities of the SDI-24.

An increase in dry days has been detected by Gemmer et al. (2011) for the same precipitation time series. Furthermore, increases in the magnitude of indices describing dryness, and a prolongation of dry periods with an opposing shortening of wet periods were identified by Fischer et al. (2011). These findings can explain the long-term dry periods that we observed in the SPI-24 and SDI-24 during the second half of the observed time period. It might also explain why the short-term cycles, around 3-4 yr, shifted to slightly longer periodicities, which would indicate innerannual changes. Further noticeable are change points in precipitation indices in 1985/1986 and 2003/2004 that were detected by Fischer et al. (2012). Both change points mark the start of the two distinct dry periods in the SPI-24 and
SDI-24. To some extent, Gemmer et al. (2011) and Fischer et al. $(2011,2012)$ link the observed changes to the weakening of the East Asian summer monsoon (EASM). This would explain the driving force of the 11-14.7 yr oscillation in precipitation.

Compared to earlier studies, our approach analyzes longterm periods and periodicities. This disaggregates extreme events and allows a broader view on climatological and hydrological statuses. Long-term precipitation cycles can be compared with the river discharge in this standardized approach. This new information on dry and wet periods is important to consider in any water-related planning for the $\mathrm{Xi}$ jiang River.

The extrapolation of periodicities is a statistical prediction by the fast Fourier transform and not based on modelling results from global or regional climate models. It is assumed that significant periods will pertain in near future, and the extrapolation suggests certain spatial and/or temporal changes in dry and wet periods in the next two decades, but no tendencies towards significantly higher or lower magnitudes. Interestingly, the results for the first years of the extrapolation in the Beipan sub-basin are in line with the drought event that affected this area in 2009-2010. Results of the extrapolation can also be supported by the findings of Sun and Ding (2010) who used a multi-model ensemble of general circulation models and projected an increase in summer precipitation for the whole of South China after the 
2040s. Similarly, Fischer et al. (2013) projected climate extremes in the Zhujiang River basin, using the regional climate model CCLM, and did not identify any significant trends in precipitation extremes for the period 2011-2050. Zeng et al. (2012) applied the outputs from the general circulation model ECHAM5 to an artificial neural network to project future river discharge of the Yangtze River and did not identify any obvious trends.

Based on these findings, we can draw the hypothesis that it is more important to investigate periodic events than trends or extremes. This hypothesis is supported by the statistical approach used in this study as compared to a physical or dynamical approach. Although we are unable to reliably predict the stability of the periodicities with statistical spectralanalysis methods (Ghil et al., 2011), we can put higher confidence in short-term extrapolations. These rely on observed significant periodicities and not only on near-future projections of global or regional climate models (Becker et al., 2008).

In future, a physically based approach can be used to test this hypothesis at a smaller regional scale and to consider regional disparities. A recent example can be drawn for the Beipan sub-basin. Our extrapolation shows extreme dry conditions in 2008-2009 that are spatially and temporally in line with the observed long-term dry event that occurred in Southwest China in 2009-2010 (Lü et al., 2012). Here, an anomalous weakening of the vertical Asian monsoon circulation in South Asia has been found responsible for this dry event. The extrapolation for Beipan takes a different course than that of the other sub-basins. The newly available information on the 2009-2010 drought proves the extrapolation to be correct. It has yet to be confirmed whether the magnitudes of the peaks are precise.

The PCA shows regional disparities in the SPI-24 for the sub-basins. The area-averaged SPI-24 for the Xijiang River basin matches the SDI-24, and each sub-basin has different long-term dry and wet periods. At a regional level, any significant changes of precipitation in the sub-basins will change the discharge and long-term dry and wet periods. This factor might have been underestimated in previous studies (e.g. Zhang et al., 2008). By applying the weighted SPI-24, it can be concluded that Beipan has a distinct impact on the Xijiang River's hydrology, especially during dry conditions such as in 2008-2009. Therefore, the methodology proves to be suitable for detecting significant periodicities and regional disparities in long-term dry and wet periods.

Our initial investigation on long-term dry and wet periods and periodicities did not show any inter-connection with large-scale atmospheric circulation indices (e.g. El NiñoSouthern Oscillation (ENSO), Madden-Julian oscillation [MJO]). Such physical explanations for the observed periodicities are required to gain more confidence on the stability of the cycles and, hence, of the reliability of the extrapolation for the future (Ghil et al., 2011). Interestingly, several studies have found similar periodicities of dry and wet events for different regions worldwide, such as China, Europe and India (Bordi et al., 2004b, 2007; Boryczka and Stopa-Boryczka, 2006; Subash et al., 2011). Studies by Bordi et al. (2003, 2004a), Fischer et al. (2012), Gemmer et al. (2011), Lü et al. (2012), and Zhang et al. (2008) suggest that several largescale atmospheric circulations cause changes in the strength of the East Asian monsoon, which causes changing periodicities, change points, and trends in precipitation pattern. Nonetheless, the extrapolation of periodicities for the next decades provides valuable information on dry and wet periods that can be used for flood risk forecasts and drought preparedness.

This study highlights the close spatiotemporal relationship of climatological dry and wet periods with hydrological dry and wet periods. Very little influence of human activities can be found in the monthly characteristics of hydrological processes. Water resource management planning and projections of hydrological long-term dry and wet periods in the Xijiang River basin should take periodicities of regional precipitation pattern into consideration.

Acknowledgements. This study was supported by the National Basic Research Program of China (973 Program) (No. 2010CB428401 and 2012CB955903), the Special Fund of Climate Change of the China Meteorological Administration (CCSF 2011-11), the National Natural Science Foundation of China (40910177), and the Sino-German Centre for Research Promotion, NSFC/DFG (GZ601). The position of Marco Gemmer is supported by the Center for International Migration and Development (www.cimonline.de).

Edited by: L. Samaniego

\section{References}

Becker, S., Hartmann, H., Coulibaly, M., Zhang, Q., and Jiang, T.: Quasi periodicities of extreme precipitation events in the Yangtze River basin, China, Theor. Appl. Climatol., 94, 139-152, 2008.

Berz, G. and Kron, W.: Überschwemmunskatastrophen und Klimaänderung: Trends und Handlungsoptions aus (Rück-) Versicherungssicht, 264-269, in: Warnsignal Klima: Genug Wasser für alle? Wissenschaftliche Auswertungen, edited by: Lozan, J. L., Graß1, H., Hupfer, P., Menzel, L., and Schönwiese, C.-D., Hamburg, Germany, 2004.

Bordi I., Fraedrich, K., Jiang, J., and Sutera, A.: Dry and wet periods in Eastern Chinawatersheds: patterns and predictability, Journal of Lake Sciences, 15, 56-67, 2003.

Bordi, I., Fraedrich, K., Jiang, J. M., and Sutera, A.: Spatiotemporal variability of dry and wet periods in eastern China, Theor. Appl. Climatol., 79, 81-91, 2004a.

Bordi I., Fraderich, K., Gerstengarbe, F.-W., Werner, P. C., and Sutera, A.: Potential predictability of dry and wet periods: Sicily and Elbe-Basin (Germany), Theor. Appl. Climatol., 77, 125-138, $2004 b$. 
Bordi, I., Fraedrich, K., Petitta, M., and Sutera, A.: Extreme value analysis of wet and dry periods in Sicily, Theor. Appl. Climatol., 87, 61-71, 2007.

Boryczka, J. and Stopa-Boryczka, M.: Cyclic Temperature and Precipitation Fluctuations in Poland in the 19th-21st Centuries, Miscellanea Geographica, 12, 43-53, 2006.

Buishand, T. A.: Some methods for testing the homogeneity of rainfall records, J. Hydrol., 58, 11-27, 1982.

China Daily: China's 3rd-largest hydropower station to be fully operating this year, in: China Daily, 2 September 2008, available at: http://www.chinadaily.com.cn/china/2008-09/02/ content_6991918 (last access: 19 January 2012), 2008.

Dai, S. B., Yang, S. L., and Cai, A. M.: Impacts of dams on the sediment flux of the Pearl River, southern China, Catena, 76, 3643, 2008.

Feng, S., Nadarajah, S., and Hu, Q.: Modeling Annual Extreme Precipitation in China Using the Generalized Extreme Value Distribution, J. Meteorol. Soc. Jpn., 85, 599-613, 2007.

Fischer, T., Gemmer, M., Liu, L., and Su, B.: Precipitation Trends and dryness/wetness pattern in the Zhujiang River Basin, South China, 1961-2007, Quaternary Int., 244, 138-148, 2011.

Fischer, T., Gemmer, M., Liu, L., and Jiang, T.: Change-points in climate extremes in the Zhujiang River Basin, South China, 1961-2007, Climatic Change, 110, 783-799, 2012.

Fischer, T., Menz, C., Su, B., and Scholten, T.: Simulated and projected climate extremes in the Zhujiang River Basin, South China, using the regional climate model COSMO-CLM, Int. J. Climatol., in press, 2013.

Gao, C., Gemmer, M., Zeng, X., Liu, B., Su, B., and Wen, Y.: Projected Streamflow in the Huaihe River Basin (2010-2100) using Artificial Neural Networks (ANN). Stochastic Environmental Research and Risk Assessment, 24, 685-697, 2010.

Gemmer, M., Jiang, T., Su, B. D., and Kundzewicz, Z. W.: Seasonal precipitation changes in the wet season and their influence on flood/drought hazards in the Yangtze River Basin, China, Quaternary Int., 186, 12-21, 2008.

Gemmer, M., Fischer, T., Jiang, T., Su, B., and Liu, L.: Trends of Precipitation Extremes in the Zhujiang River Basin, South China, J. Climate, 24, 750-761, 2011.

Ghil, M., Yiou, P., Hallegatte, S., Malamud, B. D., Naveau, P., Soloviev, A., Friederichs, P., Keilis-Borok, V., Kondrashov, D., Kossobokov, V., Mestre, O., Nicolis, C., Rust, H. W., Shebalin, P., Vrac, M., Witt, A., and Zaliapin, I.: Extreme events: dynamics, statistics and prediction, Nonlinear Proc. Geoph., 18, 295350, 2011.

Jiang, T., Chen, Y. D., Xu, C., Chen, X., Chen, X., and Singh, V. P.: Comparison of hydrological impacts of climate change simulated by six hydrological models in the Dongjiang Basin, South China, J. Hydrol., 336, 316-333, 2007.

Klein Tank, A. M. G., Zwiers, F., and Zhang, X.: Guidelines on - Analysis of extremes in a changing climate in support of informed decisions for adaptation. World Meteorological Organisation (WMO), Climate Data and Monitoring, WCDMP-No. 72, WMO-TD No. 1500, Geneva, Switzerland, 2009.

Liu, L. L., Liu, Z. F., Ren, X. Y., Fischer, T., and Xu, Y.: Hydrological impacts of climate change in the Yellow River Basin for the 21st century using hydrological model and statistical downscaling model, Quaternary Int., 244, 211-220, 2011.
Lloyd-Hughes, B. and Saunders, M. A.: A drought climatology for Europe, Int. J. Climatol., 22, 1571-1592, 2002.

Lü, J. M., Ju, J. H., Ren, J. Z., and Gan, W. W.: The influence of the Madden-Julian Oscillation, activity anomalies on Yunnan's extreme drought of 2009-2010, Sci. China Earth Sci., 55, 98112, 2012.

McKee, T. B., Doesken, N. J., and Kleist, J.: The relationship of drought frequency and duration to time scales, Preprints Eighth Conf on Applied Climatology, Anaheim, CA. Am. Meteor. Soc., Boston, 179-184, 1993.

Mishra, A. K. and Singh, V. P.: A review of drought concepts, J. Hydrol., 391, 202-216, 2010.

Nalbantis, I. and Tsakiris, G.: Assessment of hydrological drought revisited, Water Resour. Manage., 23, 881-897, 2009.

Qian, W. and Lin, X.: Regional trends in recent temperature indices in China, Meteorol. Atmos. Phys., 90, 193-207, 2005.

Santos, J. F., Portela, M. M., and Pulido-Calvo, I.: Regional Frequency Analysis of Droughts in Portugal, Water Resour. Manage., 25, 3537-3558, 2011.

Schönwiese, C.-D.: Praktische Statistik für Meteorologen und Geowissenschaftler, 4th Edn., Gebrüder Bornträger Verlagsbuchhandlung, Berlin, Stuttgart, 302 pp., 2006.

Subash, N., Sikka, A. K., and Ram Mohan, H. S.: An investigation into observational characteristics of rainfalland temperature in Central Northeast India - A historicalperspective 1889-2008, Theor. Appl. Climatol., 103, 305-319, 2011.

Sun, Y. and Ding, Y. H.: A projection of future changes in summer precipitation and monsoon in East Asia, Sci. China Earth Sci., 53, 284-300, 2010.

Torrence, C. and Compo, G. P.: A practical guide to wavelet analysis, B. Am. Meteorol. Soc., 79, 61-78, 1998.

Varis, O., Kummu, M., and Salmivaara, A.: Ten major rivers in monsoon Asia-Pacific: An assessment of vulnerability, Appl. Geogr. 32, 441-454, 2012.

Waterpub: Zhujiang River, China Water Conservancy and Hydropower Press, available at: http://www.waterpub.com.cn/ JHDB/DetailRiver.asp?ID=5 (last access: 19 January 2012), 2012.

Wilks, D. S.: Statistical Methods in the Atmospheric Sciences, 2nd Edn., Elsevier Inc., USA, 649 pp., 2006.

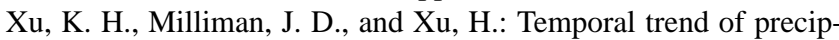
itation and runoff in major Chinese Rivers since 1951, Global Planet. Change, 73, 219-232, 2010.

Zeng, X., Kundzewicz, Z. W., Zhou, J., and Su, B.: Discharge projection in the Yangtze River basin under different emission scenarios based on the artificial neural network, Quaternary Int., 282, 113-121, 2012.

Zhai, J. Q., Liu, B., Hartmann, H., Su, B. D., Jiang, T., and Fraedrich, K.: Dryness/wetness variations in ten large river basins of China during the first 50 years of the 21 st century, Quaternary Int., 226, 101-111, 2010a.

Zhai, J. Q., Su, B. D., Krysanova, V., Vetter, T., Gao, C., and Jiang, C. T.: Spatial variation and trends in PSDI and SPI indices and their relation to streamflow in 10 large regions of China, J. Climate, 23, 649-663, 2010b.

Zhai, L. X. and Qi, F.: Spatial and temporal pattern of precipitation and drought in Gansu Province, Northwest China, Nat. Hazards, 49, 1-24, 2009. 
Zhang, Q., Jiang, T., Gemmer, M., and Becker, S.: Precipitation, temperature and runoff analysis from 1950 to 2002 in the Yangtze basin, China, Hydrol. Sci., 50, 65-80, 2005.

Zhang, Q., Xu, C.-Y., and Zhang, Z.: Observed changes of drought/wetness episodes in the Pearl River basin, China, using the standardized precipitation index and aridity index, Theor. Appl. Climatol., 98, 89-99, 2009.

Zhang, S., Lu, X. X., Higgitt, D. L., Chen, C. T. A., Han, J., and Sun, H.: Recent changes of water discharge and sediment load in the Zhujiang (Pearl River) Basin, China, Global Planet. Change, 60, 365-380, 2008.
Zhao, G., Mu, X., Hoermann, G., Fohrer, N., Xiong, M., Su, B. D., and $\mathrm{Li}, \mathrm{X}$.: Spatial patterns and temporal variability of dryness/wetness in the Yangtze River Basin, China, Quaternary Int., $282,5-13,2012$. 